San Jose State University

SJSU ScholarWorks

Master's Theses

Master's Theses and Graduate Research

1989

\title{
Factors influencing early retirement among registered nurses in the San Francisco bay area : a descriptive study
}

Phyllis L. Alexander

San Jose State University

Follow this and additional works at: https://scholarworks.sjsu.edu/etd_theses

\section{Recommended Citation}

Alexander, Phyllis L., "Factors influencing early retirement among registered nurses in the San Francisco bay area : a descriptive study" (1989). Master's Theses. 3175.

DOI: https://doi.org/10.31979/etd.6pt2-jt8t

https://scholarworks.sjsu.edu/etd_theses/3175

This Thesis is brought to you for free and open access by the Master's Theses and Graduate Research at SJSU ScholarWorks. It has been accepted for inclusion in Master's Theses by an authorized administrator of SJSU ScholarWorks. For more information, please contact scholarworks@sjsu.edu. 


\section{INFORMATION TO USERS}

The most advanced technology has been used to photograph and reproduce this manuscript from the microfilm master. UMI films the text directly from the original or copy submitted. Thus, some thesis and dissertation copies are in typewriter face, while others may be from any type of computer printer.

The quality of this reproduction is dependent upon the quality of the copy submitted. Broken or indistinct print, colored or poor quality illustrations and photographs, print bleedthrough, substandard margins, and improper alignment can adversely affect reproduction.

In the unlikely event that the author did not send UMI a complete manuscript and there are missing pages, these will be noted. Also, if unauthorized copyright material had to be removed, a note will indicate the deletion.

Oversize materials (e.g., maps, drawings, charts) are reproduced by sectioning the original, beginning at the upper left-hand corner and continuing from left to right in equal sections with small overlaps. Each original is also photographed in one exposure and is included in reduced form at the back of the book.

Photographs included in the original manuscript have been reproduced xerographically in this copy. Higher quality 6" x 9" black and white photographic prints are available for any photographs or illustrations appearing in this copy for an additional charge. Contact UMI directly to order.

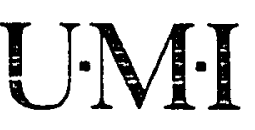

University Microfilms International

A Bell \& Howell Information Company

300 North Zeeb Road, Ann Arbor. MI 48106-1346 USA

$313 / 761.4700 \quad 800 / 521.0600$ 


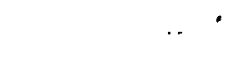


Order Number 1399601

Factors influencing early retirement among registered nurses in the San Francisco bay area: A descriptive study

\author{
Alexander, Phyllis Littlefield, M.S.
}

San Jose State University, 1989

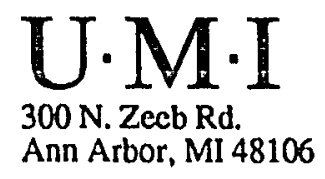





\title{
FACTORS INFLUENCING EARLY RETIREMENT \\ AMONG REGISTERED NURSES IN THE \\ SAN FRANCISCO BAY AREA: \\ A DESCRIPTIVE STUDY
}

\author{
A Thesis \\ Presented to \\ The Faculty of the Department of Nursing \\ San Jose State University \\ In Partial Fulfillment \\ of tine Requirements for the Degree \\ Master of Science
}

By

Phyllis L. Alexander

December 1989 


\section{APPROVED FOR THE DEPARTMENT OF NURSING}

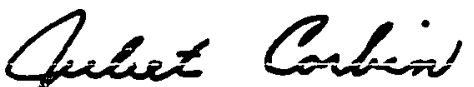

Fuliet Corbin, DNSc.

Mary Geeve

Mary Reeve, Ed.D

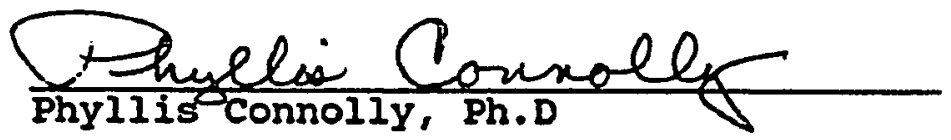

ADPROVED FOR THE UNIVERSITY

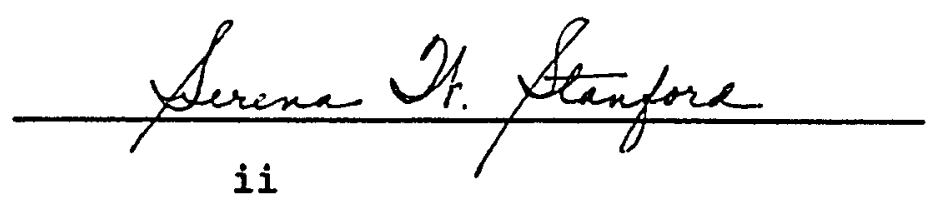




\section{ACKNOWLEDGEMENTS}

This paper would have not been completed without the tireless effort, support and encouragement of my mentor and friend, Julie Corbin. Her positive attitude gave me hope during some of my more frustrating moments, and gave me the strength to persevere. To Julie, a sincere thank you.

Also, I would like to acknowledge the support of my husband, Tom. He was the "prod" that kept me going. He was also helpful in teaching me computer applications such as word processing and Lotus 123, as weII as in eajiting the rinal manuscript. Thank you for your time, understanding, and patience. 


\section{Abstract \\ FACTORS INFLUENCING EARLY RETIREMEN' \\ AMONG REGISTERED NURSES IN THE \\ SAN FRANCISCO BAY AREA: \\ A DESCRIPTIVE STUDY}

by Phyllis I. Alexander

The purpose of this exploratory descriptive study was to determine the factors that influence registered nurses to retire before age 62 from their profession. The findings from the study were derived from data collected from a questionnaire designed by the researcher. It was administered to 14 retired nurses located in the San Francisco bay area who met the sample criteria. The questionnaire was composed of 40 questions that addressed two major areas both of which may have influenced nurses to retire early.

The results of the study indicate that registered nurses retire early from their profession for two primary reasons: (1) job stress, and (2) being financially able. Job stress was found to influence the decision to retire early in a large portion of the sample, and seemed to stem from low job satisfaction. The financial ability to retire appeared to be a "means to the end." 
TABLE OF CONTENTS

Page

LIST OF TABLES • . • • • . . . . . . . . . . . vii

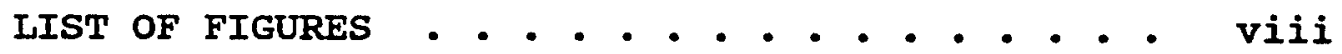

Chapter

1. INTRODUCTION . . . . . . . . . . . . 1

Statement of the Problem . . . . . . . 2

Research Question . . . . . . . . . 2

Purpose and Need . . . . . . . . . 3

Definition of Terms . . . . . . . . . 4

Research Design . . . . . . . . . 5

Setting and Sample Population . . . . . 6

Instrument . . . . . . . . . . . 7

Scope and Iimitations . . . . . . . . 7

2. CONCEPTUAL FRAMEWORK AND REVIEW OF RELATED

LITERATURE • • • • • • • • • • • • . . 9

Conceptual Framework . . . . . . . . . 9

Review of the Related Literature . . . . 14

3. RESEARCH DESIGN • . . . . . . . . . . . 22

The Research Questionnaire . . . . . . 22

The Research Setting and Sample . . . . . 25

Data Collection . . . . . . . . . . 27

Data Analysis . . . . . . . . . . . 28

Limitations . . . . . . . . . . . 29 
4. ANALYSIS OF THE DATA . . . . . . . . . 32

The Sample Population . . . . . . . . 34

Reasons for Early Retirement . . . . . . 36

Demographics of Early Retirement . . . . . 38

Professional Perceptions and Early

Retirement . . . . . . . . . . . 44 44

Content Analysis . . . . . . . . . . . 49

5. CONCLUSIONS AND RECOMMENDATIONS • . • • . . 54

Registered Nurses' Reasons for Early

Retirement . . . . . . . . . . . 55

Interpretation of the Results From the

Perspective of the Conceptual Framework . . 57

Recommendations . . . . . . . . . 59

REFERENCES . . . . . . . . . . . . . . 64

APPENDIXES

A. Cover Letter . . . . . . . . . . 69

B. Consent Form .. . . . . . . . 71

c. Questionnaire . . . . . . . . 73 


\section{LIST OF TABLES}

Table

Page

1. Total Responses to Questionnaire Question \#20: What is the main reason you retired? . . . . . . . . . . . . .

2. Comparison of Demographic Characteristics of Subjects Citing Job Stress Versus Financial Ability as the Primary Reason for Retirement . . . . . . . 39

3. Professional Perceptions of subjects Citing Job Stress Versus Financial Ability as the Primary Reason for Retirement . . . . . . . . . . . 46 


\section{LIST OF FIGURES}

Figure

Page

1. A Conceptual Framework of Factors

Influencing Early Retirement Among

Registered Nurses . . . . . . . . . .

12

viii 


\section{Chapter 1}

\section{INTRODUCTION}

The "nursing shortage" in America has become an issue of national concern. The California Association of Hospitals and Health Systems (CAHHS) recently commissioned a study to: (a) determine the scope of the problem, (b) determine its causes, (c) and recommend solutions (California Association of Hospitals and Health Systems, 1988).

The published findings of this study suggest that there is indeed a nursing shortage. California hospitals reported an increase in the Registered Nurse (RN) vacancy rate from 8.98 in 1986 to $9.7 \%$ in 1987. Nationally, the $R N$ vacancy rate in hospitals is reported to be $11.3 \%$ (CAHHS, 1988).

The California study found the shortage to be related to both an increase in the demand for RWs and a decrease in the rate of supply (CHHS, 1988). A higher staffing ratio of nurses to patients is needed to provide safe patient care because of an increase in patient acuity. Yet between the years of 1986 to 1987 , there was a 98 decrease in nurses graduating from nursing schools in California (CAHHS, 1988). Not only are fewer people entering the nursing profession, but a 
large number of registered nurses are no longer practicing their profession.

A 1980 report from the United States Department of Health and Human Services Public Health Service reported that there are 388,537 registered nurses who are not employed in nursing. Of this group, only 85,823 are 60 years or older (Chan Fowles, 1980).

In summary, nurses comprise a vital element of the health care delivery system in America today. The entire system is rapidly changing and the need for qualified, experienced nurses is at its peak. Contrary to this increasing need, a large number of older, more experienced nurses are leaving the profession prior to age 62 years, the traditional age of retirement for women (Dittmar, 1983).

statement of the Problem

The purpose of this study was to determine the factors that influence registered nurses to leave the profession before the traditional age of retirement. Research Question

The specific question addressed in this study was: What factors influence registered nurses, between the ages of 45 and 61 who have worked for ten or more consecutive years in nursing, to retire early. 
Purpose and Need

It is estimated that $16 \%$ of the registered nurses living in America today, who are less than 60 years of age, have retired from the nursing profession (Johnson, 1985). This fact is disturbing considering the current and future demands that are being placed upon the health delivery system by regulatory agencies for high quality nursing care (McKibbin, 1982).

Changing strategies in governmental health care payment systems are pressuring hospitals to reduce nonessential support personnel and to recruit and hire more experienced professionals (CAHHS, 1988). During the early 1980's, this change in hiring policies helped to create a market phenomena known as the "nursing shortage," which, in turn, caused an unprecedented bidding war among hospitals for the services of registered nurses (CAHHs, 1983). If hospitals are not able to meet their needs by filling vacancies with registered nurses, other health care workers may fill the positions, thus encroaching upon the practice of nursing as it exists today.

The California Association of Hospitals and Health Systems concludes that there is an increasing demand for registered nurses throughout the health care 
industry, but the number of these professionals available in the work force is decreasing. The increased need to hire and retain professional nurses is being fueled by: (a) a society with a large percentage of the population over 65; (b) rapid changes in diagnostic and treatment technologies; and (c) increasing demands by regulatory agencies for patient care accountability. In addition, more attractive career alternatives appear to have reduced the number of men and women who choose nursing as a profession (National Commission on Nursing, 1981).

Compounding the problem of a reduced supply of new professionals, is the exodus of experienced, mature registered nurses from the nursing profession. The purpose of this study was to explore the factors that influence mature nurses, who have worked at least ten

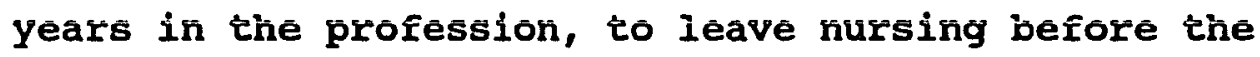
usual retirement age.

\section{Definition of Terms}

For the purpose of this study, the following terms are defined:

1. Registered nurse: An individual who has passed state requirements and is licensed by the state to perform all clinical activities described within the 
Nurse Practice Act (Bower \& Bevis, 1979, p. 10).

2. Nurse Practice Act: Nurse practice acts are the state laws that govern how, when, where, with whom, and under what conditions nurses can provide care (Bower, \& Bevis, 1979, p. 10).

3. Nursing Process: The process of assessment, diagnosis, planning, implementation, and evaluation of nursing care. Its goal is to facilitate the optimal level of functioning by the client (Bower \& Bevis, 1979, p. 166).

4. San Francisco Bay area: The area encompassed within a 100 mile radius of the city of San Francisco, California.

5. Early retirement: $A$ nurse with at least ten years experience who leaves the nursing profession after age 45 and before age 62 .

Research Desigñ

This exploratory study used a descriptive survey design. No specific hypothesis was tested. Rather, the investigator engaged in a fact-finding mission that had no preconceived outcomes.

Data were gathered in this study on the following variables: (a) age at retirement, (b) gender, (c) retirement income, (d) educational level, (e) 
membership in labor unions, (f) marital status at retirement, (g) existence of job-related stress, (h) number of years in the profession at retirement, (i) degree of satisfaction with the profession, (j) degree of satisfaction with last nursing related employer, (k) health status at retirement, (1) salary at retirement, and (m) primary reason for retirement.

Variables controlled for the study design were: (a) age at retirement limited to 45 to 61 years old, (b) number of years in the profession at retirement limited to not less than ten. Descriptive statistics were used to analyze the data. Setting and Sample Population

The research question was explored by surveying a sample of 14 registered nurses living in the San Francisco Bay area. At the time of their retirement, these nurses were between the ages of 45 and 61 , and had worked for ten or more consecutive years in nursing.

Several attempts to locate potential subjects through professional channels failed. The final sample of 14 was obtained through an informal network of professional colleagues known to the investigator. Immediate acquaintances were asked to identify other 
potential subjects through their sphere of professional contacts. This type sampling is called snowball sampling (Polit \& Hungler, 1987).

Instrument

Data were gathered by means of a Nursing Retirement Questionnaire designed by the investigator (see Appendix $c$ ). The questionnaire was tested for clarity by a small group of nursing colleagues prior to general distribution to the study sample. These responses were not included in the final data analysis. Revisions were made based on their suggestions. The subjects' rights were protected by informed consents (see Appendix B). The study was approved by the Institutional Review Board on Human Subjects at San Jose State University.

Scope and Limitations

The study sample was composed of 14 individuals who met the study criteria, and who were willing to complete the study questionnaire. This small sample size is the major limitation of the study, as one cannot generalize the findings from such a small sample to the larger population of retired nurses. Another limitation of the study is that the data gathering instrument was not thoroughly tested for 
validity and reliability. Finally, the responses may have been biased because of the San Francisco Bay area's high per capita income and cost of living. 
Chapter 2

CONCEPTUAL FRAMEWORK AND REVIEW OF RELATED LITERATURE

Conceptual Framework

The conceptual framework for this study was developed to provide insight into the type of data to be solicited from the study sample, as well as to serve as a general guide for interpreting the study's results (Polit \& Hungler, 1987). It is based upon King's concept of the nursing profession, which states that nursing is an interaction of personal, interpersonal, and social systems (King, 1981). Although there are no specific publishea reports of how King's theory might be used in practice (Parse, 1987), this model seemed appropriate for describing the forces that influence nurses to take an early retirement.

According to king, (1981, p. 82) a personal system is a unified complex whole that identifies goals and selects means to achieve them. She defines an interpersonal system as "a process of interaction in which two or more human beings communicate with the enviromment to achieve goals that are valued" (King, 1981, p. 82). Social systems are viewed as sources of authority and power. Authority provides order, while power is the ability to achieve goals, and is defined 
as "the process whereby one or more persons influence other persons in a situation" (King, 1981, p. 127). Applying King's conceptual framework to this study, the individual nurse's decision to retire from the profession prior to the expected, or traditional retirement date, is seen as the final action resulting from a number of interacting and conflicting forces. These forces are products of the nurse's personal, interpersonal, and social systems, and if in equilibrium, result in a satisfied, productive individual. Whereas if they are in conflict, they can inhibit goal achievement and result in frustration and the need to escape the situation. Retirement from the nursing profession represents the ultimate escape. Forces affecting a nurse's decision to retire early can emanate from a number of sources, some of which are internal to the work environment and some of which are external to the work environment. Or, there can be a combination of internal and external factors. The study focused on factors internal to the work environment that are known to influence work satisfaction leading to the ultimate decision to retire early. The strength of these internal factors in forcing the retirement decision may or may not be 
affected by factors external to the work environment.

In a recent study of 312 registered nurses, Mottaz (1988) reported that the major determinants of work satisfaction among nurses are (1) supervisory assistance, (2) task significance, (3) task involvement, (4) task autonomy, and (5) salary. These "determinants" can be associated with King's nursing systems concept in that they involve goal selection and achievement, and, if not met, can lead to job stress and the decision to retire early from the profession (see Figure 1).

Task significance, task autonomy, and salary can be associated with personal system goals. Mottaz (1988, p. 66) states that one of the strongest forces influencing a nurse's desire to remain in the profession is that of "task significance," or the importance of the goal of caring for the sick and injured to that nurse. This seemingly positive force, however, can be offset by negative factors such as low pay, poor working conditions, and lack of autonomy, which inhibits the achievement of goals that positively influence self-esteem.

Supervisory assistance, task involvement, and task autonomy are associated with the interpersonal system. 


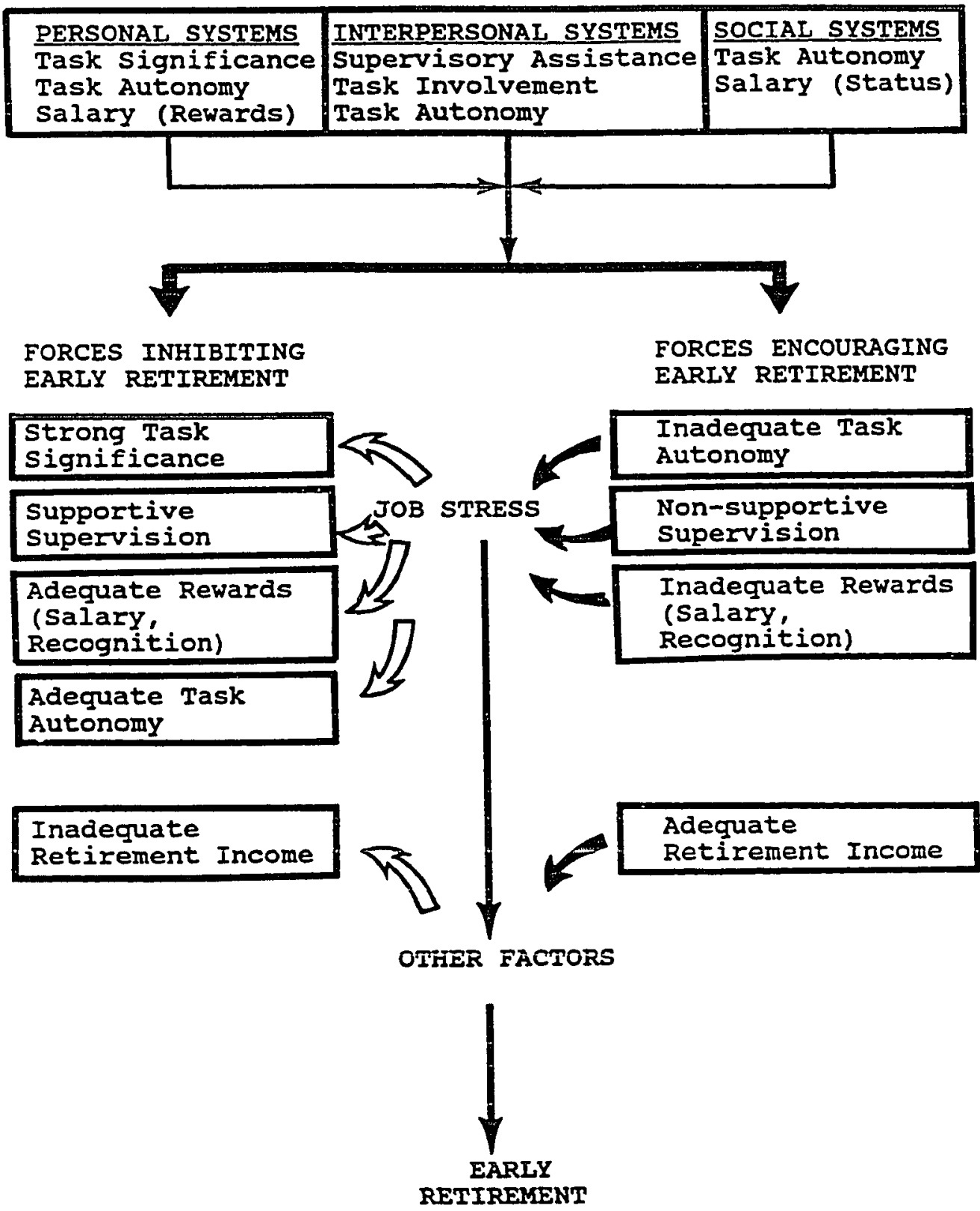

Figure 1. A conceptual framework of factors influencing early retirement among registered nurses 
Mottaz (1988) reports that owing to the bureaucratic principles currently employed throughout hospitals, task involvement is structured and task autonomy is limited for nurses. Consequently, nurses are very dependent on supervisors in the performance of daily nursing tasks, and if the nurse and supervisor are not oriented to the same goal, conflict, frustration, and job stress can occur.

Task autonomy and salary are associated with the social system or power structure of the work environment. If, because of a lack of autonomy or stature (represented by salary level) the nurse feels inadequate to achieve goals, this too may result in frustration, stress, and the desire to escape the environment. A strategy employed by nurses to achieve more power in the social system is the formation of collective bargaining units. These efforts have had some success in increasing nurses' salaries but have had little success in increasing nurses' task autonomy and reducing job stress.

The failure to achieve desired goals can result in job stress, which, in turn, can lead to early retirement. stress is perceived as a dynamic state with humans interacting with the environment to 
establish equilibrium. According to King, (1981) stressors are physical, environmental, chemical, physiological, emotional, and social. Each person responds differently to the same stressors.

In some cases job stress alone is sufficient to force a nurse into the decision of early retirement. However, in most instances the early retirement is supported by an ability to be financially independent. Review of the Related Literature There have been few research studies reported in the management science literature specifically related to identifying factors that lead to early retirement among American nurses. The literature does, however, provide descriptive facts that give some insight into the problem.

Nursing manpower statistics, published by the American Nurses' Association (ANA) (Johnson, 1985), reports that the number of registered nurses in November 1980 was 388,537 . Of this amount, nurses aged 50 years and over numbered 141,220 . This represents over one third of the entire nursing population. In the age category 50 to 59 years, 55,397 nurses were not employed and furthermore were not seeking employment in nursing. 
Assuming that some of these nurses were physically disabled, and discounting an estimated $15 \%$ for physical infirmities, a potential of 47,207 experienced nurses would be available for the work force. Therefore, given the 302,417 registered nurses under 60 years of age, 47,207 , or $16 \%$, had left the profession for reasons other than poor health.

Other studies have investigated factors leading to early retirement among American workers in general. One such study (Morse, Dutka, \& Gray, 1983) found four general factors that influenced early retirement: (a) the ability to afford to retire, (b) health related reasons, (c) feelings held by the worker that they had worked long enough, and (d) pressures of the job or feelings that the older worker was unfairly treated by the employer.

Morse, et al. (1983) also provided some explanations concerning the relationship between early retirement and the gender of the worker. out of the 850 respondents to the study questionnaire there was an equal number of men and women. The study found that at the time of retirement women earned an average of $60 \%$ of the male salary and only one out of two women were married as opposed to nine out of ten men. 
One of the shortcomings of the Morse, et al. (1983) study was that it did not categorize the factors that influenced early retirement on the basis of gender. Rather, it focused on the finding of a disproportionately small number of females in the management ranks and the relative low pay of the female worker. Since nursing is a predominantly female occupation, more insight into why females, in general, retire early could have been helpful in describing why many nurses retire early.

Rix and Fisher (1982) studied retirement and age policy. Their study shows that women are influenced by the same retirement incentives as men. Since women are more apt to leave and re-enter the labor force during their years in the work force, they are more difficult to track. However, the Rix and Fisher (1982) study concluded that married women are influenced into taking an early retirement by factors such as: higher levels of assets and income, home equity, spouse's social security wealth, and pension wealth. A woman's own social security and pension wealth did not influence early retirement.

In the Rix and Fisher (1982) study reported above, another finding important to nursing retirement was the 
wage factor. Women were found to be two to three times as responsive to higher wages than men. Thus, women were more likely to be influenced to remain in the work force by higher wages than were men.

Another factor found to influence early retirement in women by the Rix and Fisher (1982) study was elderly parents in the home. Women in general, and nurses in particular, are the traditional care givers to elderly parents, spouses, and other dependent family members.

other research studies relevant to the general subject failed to differentiate between male and female respondents. Barfield and Morgan (1970) suggest that the primary reasons for early retirement in a group of auto workers were planned early retirement and poor health. Using the Cornell longitudinal study, Streib and Schneider (1971) found that the attitude toward retirement was the most important factor influencing retirement adjustment. They found that people who retired early were generally more satisfied with their decision to retire than those who retired later. Beutell and Brenner (1987), in a study of 317 human resource administrators, found that health problems ranked first and benefit packages second as factors that influence early retirement. Poor health 
was the number one factor influencing early retirement for all workers in the United states according to a study reported by Chan and Fowles (1980).

with the implementation of social security, the proportion of workers retiring before age 65 has continued to rise. From 1962, the first year of early retirement benefits for both male and female, to 1977 , male early retirement rose from $51 \%$ to $68 \%$, and in females it increased from $62 \%$ to $78 \%$. This same study showed marriage to have opposite effects on early retirement for men versus women. Married men were less likely to take early retirement but married women were more likely to retire early (Chan \& Fowles, 1980).

The point is made in The Encyclopedia of Aging, (Maddox, 1987) that retirement is a new development in industrialized nations with increased productivity. It is made possible for significant numbers by government pension plans. Income has increased at twice the rate of inflation over the past 25 years (Chan \& Fowles, 1980); thus, more money is available for early retirement (defined by the social security Administration as before age 65). Issues surrounding retirement of registered nurses in particular have been addressed to some degree by the 
American Nurses' Association. McKibbin (1982) gave an overview of the economic issues that were specific to nursing. She suggested that a lack of substantial financial strength and retirement benefits existed in the nuxsing profession.

The Mckibbin (198i) paper reinforced the findings of a survey conducted by the Chamber of Commerce of the United states (1981). That survey found that benefit packages provided by hospitals were low in comparison to benefit packages provided by other industries. The only industry that was lower in benefits as a percentage of payroll was the wholesale and retail trades. In regard to employee pension plans, hospitals contributed $3.7 \%$ of total payroll dollars to such plans as compared to an average $6.0 \%$ contribution made by other non-manufacturing industries.

Another ANA publication (Dittmar, 1983) focused on retirement income and benefit issues for registered nurses. This study found that being able to afford to retire was not a major factor influencing the decision of registered nurses to retire early. Moreover, Dittmar concluded that employers could use better, more flexible retirement and pension plans as effective mechanisms for attracting and retaining highly 
qualified, stable and loyal work forces (Dittmar, 1983, p. 18)

Todd and Wallace (1987) headed a study in North Carolina to explore the feasibility of inactive nurses returning to the work force to decrease the nursing shortage. A questionnaire was sent out to 600 registered nurses who were classified as unemployed by the North Carolina Board of Registered Nurses. The questionnaire included (1) demographics, (2) reasons for not being actively engaged in nursing at this time, (3) interest in seeking nursing employment, (4) educational level, and (5) work experience. The questions were closed and open-ended.

The age range of respondents was 23 to 79 , with a mean of 50. The percentage of nurses under 65 was 768 . Todd and Wallace (1987) found that "better working conaitions" was given as the main factor that would influence nurses to return to work. Responses were not presented by age category.

Early retirement and job turnover have been also related to job satisfaction. De cotiis and summers (1987) show that job satisfaction and commitment were equally predictive of motivation and job performance. A study by Brooke, Russell and Price (1988) found 
relationships between job satisfaction, job involvement, and organizational commitment.

other publications suggest alternative factors influence early retirement in registered nurses. Sloan (1975) points out that the government has historically intervened to control the distribution, supply, and demand of nurses. Because the cost of health care is perceived to be so high, the government has placed regulatory controls on hospitals that should not exist in a free market system. Sloan suggests that these controls may directly or indirectly interfere with the nurse's ability to fulfill a perceived role, impose stress on the individual, and influence a nurse's decision to retire early.

In summary, the literature provides insight into why American workers, in general, retire early, and aiso suggests why men choose eariy retirement. In addition, the literature is rich with findings suggesting factors related to job satisfaction among nurses, but says little about how job satisfaction may lead to early retirement. From these reports one can only speculate as to the question of why registered nurses choose early retirement. 


\section{Chapter 3}

\section{RESEARCH DESIGN}

The purpose of this study was to identify those factors that influence registered nurses to take early retirement. The study used a non-experimental descriptive design. Findings were derived from data collected from a researcher designed questionnaire, which was administered to a sample of retired nurses who met a pre-determined set of criteria. The research process consisted of four steps: (a) designing and testing the questionnaire, (b) identification and solicitation of the study population sample, (c) data collection, and (d) data analysis. The Research Questionnaire

The instrument used to collect data was a questionnaire developed by the investigator specifically for this study. The researcher named the instrument FINER (Factors Influencing Nurses Early Retirement) (see Appendix c). The questionnaire was modeled after one used in the study of early retirement of auto workers (Barfield Morgan, 1970). It was modified to apply to registered nurses and was composed of 37 multiple choice, closed-ended questions and three open-ended questions. 
The questionnaire was pre-tested and evaluated for clarity and content by two registered nurse colleagues and a nursing professor at San Jose state University. Appropriate changes were made. The study was approved by the Institutional Review Board for Human subjects at San Jose State University for protection of subjects. The questionnaire asked for responses to questions regarding: (a) gender, (b) race, (c) educational level, (d) number of years in the profession at retirement, (e) professional position at time of retirement, (f) clinical area assignment at time of retirement, (g) number of years in area of last assignment, (h) salary at retirement, (i) retirement income, (j) family income at retirement, (k) marital status at retirement, and (1) membership in labor unions. It used a varied format consisting of multiple choice, single response, and open-ended questions. The key question of the study addressed nurses' main reason for taking early retirement. Five possible responses were provided: (a) health reasons, (b) being financially able, (c) job stress, (d) encouraged by management, and (e) other. In this, as in the three other closed-ended questions, an answer option of "other" was provided as a safety measure (Polit \& 
Hungler, 1987).

In retrospect, the questionnaire wording was not sufficiently explicit to avoid multiple responses to questions intended to be single response. This defect in the instrument proved troublesome for the investigator, as it made it difficult to determine the primary reason given for the respondents' retirement. A response that required a "ranking" of factors would have been more useful to the investigator.

The remaining multiple choice, closed-ended questions addressed the respondents' opinions of the nursing profession and attempted to identify the indirect factors that lead to a decision to retire early. These questions explored such areas as: (a) the existence of satisfaction with the profession, (b) perceived appreciation of efforts by co-workers and patients, (c) adequacy of recognition and rewards, age and job stress, and (e) adequacy of management understanding.

Two of the open-ended questions required specific answers. These questions addressed the respondent's current age and their age at retirement. The third open-ended question allowed the respondent to expound with "additional comments felt appropriate to the 
subject matter." This question provided the respondents freedom to express their opinion which, in turn, provided valuable insight into the more subtle reasons nurses take early retirement. Polit and Hungler (1987, p. 228) define self-report as direct questioning and say this method is "strong with respect to its directness and versatility."

The Research Setting and Sample The research took place in the greater San Francisco Bay area, defined as located within a 100 mile radius of the city of San Francisco, California. This area was chosen because of its convenience and because it has a large population of registered nurses. The study population was defined as registered nurses who retired between the ages 45 and 61 years, who reside in the defined geographic area, and who worked as a professional nurse for at least ten years. In order for the findings to yield statistically valid conclusions, it was estimated that the study sample should contain a minimum of 25 respondents. The investigator made several attempts to locate a sufficient number of subjects to meet this criteria. She was unsuccessful and had to settle for a sample size of 14 . 
The first method the investigator used to try to find subjects was to seek assistance from both the California Nurses' Association and the California state Board of Registered Nurses. They were asked to provide the researcher with the names and telephone numbers of nurses who met the study criteria. The investigator was informed by these agencies that their current and past registration rosters were confidential and could not be used.

The second method was to contact local hospital personnel departments and nursing service departments to solicit their help in identifying past employees who could be asked to participate in the study. The personnel departments of five local hospitals would not disclose information regarding early retirees because of the issue of confidentiality. The nursing service departments were not willing to participate.

A telephone request for assistance to a local retired nurses association yielded one willing participant, and three advertisements in local newspapers were successful in identifying two retired nurses, who met the study criteria and who were willing to participate.

Due to the difficulties encountered in obtaining 
the study sample through established data sources, the investigator was compelled to use a convenience sample of registered nurses solicited primarily through referrals from colleagues and by referrals from earlier subjects. This type of sampling is known as snowball sampling (Polit \& Hungler, 1987). Using this method, a total of 15 potential subjects was identified.

\section{Data Collection}

once a prospective study participant was identified through the methods described above, the investigator telephoned the individual, introduced herself, and explained the purpose of the study. If a retired registered nurse expressed a willingness to participate, he/she was mailed a packet of material including a cover letter (Appendix A), consent form (Appendix B), and the questionnaire (Appendix C) - A stamped addressed envelope was also included to return the completed questionnaire. Participation was voluntary.

A total of 15 questionnaire packets were mailed. Fourteen questionnaires were completed and returned. The potential subject who did not respond was contacted again by phone, and agreed to return the completed questionnaire. However, her response was never 
returned, and no further contact was made, as this could have been interpreted as coercion. The project had a 938 response rate. If the sample had been larger, this return rate would have been considered extremely good. Polit (1987) states that a response rate of $60 \%$ is sufficient for most purposes (p. 242). However, in a sample of 15 , each response carries a heavy weight, and a very high response rate is essential before even modest conclusions can be drawn from the findings. The first questionnaire was received August 31, 1987, and the last January 1, 1989. Data Analysis

Each response to the closed-ended multiple choice questions on the questionnaire was assigned a specific "address" number. As questionnaires were received, responses to the questions were entered into a lotus 123 "electronic spreadsheet." All responses from the participants were included on one spreadsheet. Each question with its respective possible responses (specific address) were represented as columns on the spreadsheet, and each participant was represented as a row on the spreadsheet.

A response of a participant was entered as a "1" in the appropriate address cell, and the lack of a 
response was considered as a "blank" in that address cell. This technique allowed the investigator to sort the data according to responses and to calculate specific response rates easily.

The primary question of the study asked nurses to state their primary reason for taking early retirement. The questionnaire allowed five possible choices of response to this question. The database was sorted according to the five potential responses.

Responses to the one open-ended question allowed the participants to express additional comments appropriate to the subject matter. Their responses were analyzed for the existence of recurring themes. As the themes were found, they were categorized and used to support or refute conclusions drawn from the limited quantitative data. All 14 participants responded to the optional open-ended question with comments that ranged from a few sentences to over three pages in length.

\section{Limitations}

The factors that influence registered nurses' decision to take early retirement are not documented in the literature, thereby giving this preliminary investigation a sense of need. However, several 
limitations of this non-experimental descriptive study are apparent.

The responses of the convenience sample used in this study cannot be said to be representative of those of the entire population of registered nurses who have retired early from the nursing profession. Another limiting factor is the method that was used for selecting the sample. It used a non-random sampling technique. The result was a sample that consisted of all white female subjects.

The questionnaire was designed by the investigator and did not allow for a ranking of responses of several key areas. This shortcoming of the research tool restricted the ability of the investigator to suggest possible relationships from the data. In addition, the questionnaire was not tested extensively for validity and reliability.

The thematic analysis of responses to the open-ended question must be recognized as potentially biased. The opinions solicited from these responses, however, were valuable in obtaining insights into the subject matter that the more quantitative data did not reveal.

By far the most serious limitation of the study 
was the small sample size. Although a number of methods for identifying and soliciting appropriate study subjects were attempted, only 15 potential research subjects were found and contacted. The final sample consisted of oniy 14 respondents, a number far from acceptable for supporting conclusions based upon statistical analysis. Owing to this limitation, the results drawn from this study can not be considered generalizable nor representative of the characteristics, opinions, and responses of the entire population of registered nurses who have left the nursing profession prior to normal retirement age. 


\section{Chapter 4}

\section{ANALYSIS OF THE DATA}

The purpose of this study was to identify the factors that influence experienced registered nurses' decisions to retire from the nursing profession prematurely. An experienced nurse was defined as one having worked at least ten years in the profession; premature retirement was defined as leaving the profession between the ages of 45 and 61 years.

The objective of the research was to determine the stated reason for retiring, based on three major areas: (a) demographic factors; (b) the subjects' perceptions of the profession, and (c) their experiences as registered nurses.

The purpose of this chapter is to present the findings of the study. The data were gathered by the investigator through a questionnaire (see Appendix c), which was distributed to 15 subjects who met the study criteria. A number of methods were attempted for securing a larger and more representative sample of the total population (see Chapter 3); however, few were successful. Fourteen of the 15 questionnaires distributed were returned. All returned questionnaires were completed. 
The questionnaire was composed of 40 questions. The key question, "What is the main reason you retired?", was closed-ended, and offered five possible choices: (a) health, (b) financially able, (c) job stress, (d) encouraged by management, and (e) other. The demographics of the sample were identified through two open-ended and 22 closed-ended questions. These questions addressed such issues as: (a) present age, (b) age at retirement, (c) gender, (d) race, (e) marital status, (f) health, (g) education, (h) years as a nurse, (i) last job position and status as a nurse, (j) union membership, and (k) personal and family wealth.

The subjects' perceptions of the nursing profession and their professional experiences were examined through one open-ended and 14 closed-ended questions. The closed-ended questions addressed the subjects' perceptions pertaining to: (a) discrimination against older nurses, (b) job stress, (c) appreciation by peers and patients, (d) adequacy of work-related rewards, (e) management support and awareness of needs, (f) adequacy of education and skills, and (g) overall professional satisfaction. The one open-ended question allowed the respondents to elaborate upon issues and 
perceptions "appropriate to the subject matter," and was used to support or refute conclusions drawn from the quantitative data.

The analysis of the data is presented in the following order: (a) a description of the general population, (b) a listing of reasons given for early retirement, (c) a descriptive breakdown and comparison of the sample characteristics for each of the primary reasons given for early retirement, (d) a descriptive breakdown and comparison of professional perceptions according to reasons given for early retirement and (e) content analysis of the qualitative data. The Sample Population

An important factor to consider when analyzing data from a sample is to understand the predominant characteristics of the population it represents. The most accurate method of describing these characteristics is through a tabular presentation of the demographic features and professional perceptions of the sample as gathered through the study questionnaire.

Another way to describe these characteristics is to define the typical subject by noting the most frequent responses to questions related to demographics 
and perceptions of the nursing profession. Using Lotus 123 to sort the data the typical subject was identified as a 61 year old white female, who retired from the nursing profession at age 57 years. She was a diploma graduate, had practiced nursing for over 25 years, and, at the time of retirement, was a full-time staff nurse, or nurse manager who had spent ten years in her last position. She was married, and her spouse was also retired; both were in good health. She had planned her retirement, and if offered, would not have accepted another position in the hospital.

During her last year of employment she made between $\$ 15,000$ and $\$ 20,000 ;$ however, her total family income at that time was over $\$ 40,000$ per year. Despite having retirement benefits other than social security, her retirement income was less than $\$ 15,000$ per year. Her family owned their home, and she felt that her retirement income was less than adequate.

The typical subject retired because of job stress and because she felt financially able to do so. She was happy that she chose nursing as a career, and would advise young persons to enter nursing. She felt that her efforts were appreciated by her co-workers and by her patients, and that her skills and education were 
adequate for the job.

Finally, the typical subject perceived job stress to increase with age, even though she felt that older nurses were not discriminated against by their supervisors or co-workers. She felt that neither the reward systems nor the level of compensation were adequate in comparison to the work expectations placed on nurses, and that the majority of those persons involved in hospital management were not aware of the problems faced by nurses.

\section{Reasons for Early Retirement}

The questionnaire permitted five choices of response to Question 20, "What is the main reason you retired?" These were: (a) health, (b) being financially able, (c) job stress, (d) encouraged by management, and (e) other. Even though the question asked for the primary reason, some respondents indicated more than one reason.

Table 1 shows the responses to the "reason for retirement" question. A total of 19 responses were received from the 14 subjects. Four of the subjects listed two reasons for retiring. of the four respondents listing two reasons, two gave "financially able" and "other" as reasons, one gave "health" and 
Table 1

Total Responses to Questionnaire Question \#20: What is the main reason you retired? $(N=14)$

\begin{tabular}{lcc}
\hline & $\begin{array}{c}\text { Number of } \\
\text { Responses }\end{array}$ & $\begin{array}{l}\text { Percentage of } \\
\text { Respondents }\end{array}$ \\
\hline Health & 1 & $7.14 \%$ \\
Financially able & 6 & $42.85 \%$ \\
Job stress & 8 & 57.148 \\
Encouraged by management & 1 & 7.148 \\
Other & 3 & $21.42 \%$ \\
\hline
\end{tabular}

Note. The sum of the responses totals 19 rather than 14 because several participants listed more than one reason for retiring. 
"job stress" as reasons, and one gave "financially able" and "job stress" as reasons.

The reason most frequently given for retirement was "job stress" (57.14\% of the sample). The next most cited reason was being "financially able" (42.85\% of the sample). The "other" category was given by $21.42 \%$ of the sample, and the "health" and "encouraged by management" responses were noted by only 7.148 of the sample.

Demographics and Early Retirement The data entered into the Lotus 123 spreadsheet were electronically sorted into two categories: (1) respondents who noted "job stress" as the primary reason for retirement, and (2) respondents who noted "financially able" as the primary reason for retirement. The data from these two groups were analyzed independentily to dečermine and describe their general demographic compositions. Data from the two groups are presented in Table 2 for comparison.

The age of the eight participants in the study who stated "job stress" as the primary reason for retirement ranged from 56 years to 62 years at the time of the study, and from 55 years to 60 years at the time of their retirement. The difference between the time 
Table 2

A Comparison of Demographic Characteristics of Subjects Citing Job Stress Versus Financial Ability as the

Primary Reason for Retirement $(N=14)$

Number of Responses

Job stress Financial Ability

Response Primary Reason Primary Reason

Marital status
a. Married
$4(50 \%)$
$4(67 \%)$
b. Not Married
4 (50\%)
$2(33 \%)$

Education
a. Diploma
$6(758)$
3 (50\%)
b. AA Degree
0 (0民)
1 (17\%)
n. BSN Degree
1 (13\%)
o (0\%)
d. Masters Degree
1 (13\%)
2 (338)

Years of Nursing
a. $10-15$ years
2 (25\%)
0 (0z)
b. $16-20$ years
o (0\%)
o (0\%)
c. 21 - 25 years
2 (25\%)
O (0z)
d. Over 25 years
4 (50\%)
$6(100 \%)$

Note. Percentages are rounded to one-tenth percent. 
Table 2 (Continued - 2)

A Comparison of Demographic Characteristics of subjects Citing Job stress Versus Financial Ability as the Primary Reason for Retirement (N = 14)

\begin{tabular}{ccc}
\hline & Number of Responses \\
\hline Job Stress & Financial Ability \\
Response & Primary Reason & Primary Reason \\
\hline
\end{tabular}

Last Nursing Position
a. Staff Nurse
$5(628)$
1 (17\%)
b. Head Nurse
1 (13\%)
1 (17\%)
c. Supervisor
1 (138)
3 (50\%)
d. Other Management
1 (138)
1 (17\%)

Union Membership
a. Union Member
3 (38\%)
3 (50\%)
b. Non Union Member
5 (63)
3 (50\%)

Family Income
a. Less than $\$ 15,000$
0 (0z)
o (08)
b. $\$ 15,000-\$ 20,000$
1 (138)
1 (17\%)
c. $\$ 20,000-\$ 30,000$
1 (13\%)
$1(17 \%)$
d. $\$ 30,000-\$ 40,000$
1 (13\%)
1 (17\%)
e. Over $\$ 40,000$
5 (62\%)
3 (50\%) 
of retirement and the time of the study ranged from one year to five years. The data for the study were collected in 1988, which means that the respondents in the "job stress" category retired over the period 1983 through 1987. In fact, only one respondent included in the "job stress" category retired in 1983; the other seven retired during the period 1985 through 1987. The six study subjects who selected "financially able" as their main reason for retirement ranged in age from 52 years to 80 years at the time of the study and from 50 years to 60 years at the time of their retirement. The difference between the time of retirement and the time of the study of this group ranged from one year to 22 years. Three members of this group retired prior to 1985, and three members retired during or after 1985.

Whether the aifference between the time of retirement of the two groups affected perceived levels of job stress or financial well-being is an interesting question. This difference was not controlled for and may be a limitation of the study. This finding, however, may be explained in light of the following. In 1983, the United states Congress passed the Medicare revisions of the Tax Equity and 
Fiscal Responsibility Act of 1982 (TEFRA), which placed hospitals at financial risk, when treating patients, who qualified under the Diagnostic Related Group (DRG) reimbursement system. Many hospitals began to feel the effects of this new payment system in 1985 and 1986. They began to implement operational changes that, in some cases, reduced nurse staffing levels and support systems with no expressed expectations of reduced nursing responsibilities or activities (Mercer, 1987). This series of events may have affected more recent nursing retirees by increasing the likelihood that "job stress" was a major factor in their decision to retire (Hospitals not immune, 1988).

In regard to the other demographic characteristics, all of the study subjects were white females, which makes racial and gender factors neutral in this analysis. The remaining demographic factors that characterize the "job stress" group and the "financially able" group are presented in Table 2.

On a percentage basis, $67 \%$ of the "financially able" group were married compared to $50 z$ of the "job stress" group; also 508 of the "financially able" group had acquired college and post graduate education degrees as compared to $26 \%$ of the "job stress" group. 
All of the six members of the "financially able" group had spent over 25 years in the nursing profession as compared to only $50 \%$ of the "job stress" group, and $63 \%$ of the "job stress" group were represented by a labor union at retirement as compared to $50 \%$ of the "financially able" group.

Another demographic characteristic analyzed considered the employment position held by the subjects prior to retirement and the level of total family income at that time. Possible responses to the employment position question included (a) staff nurse, (b) head nurse, (c) supervisor, and (d) other management. The staff nurse was considered to be a non-management position; all other options were considered as "management."

of the group selecting "job stress" as the primary reason for retirement, five subjects, or $63 \%$ of the total, held the position of staff nurse at retirement; the remaining three nurses held management positions. The composition of the "financially able" group was one staff nurse, or $17 \%$ of the total, and five managers. The total family income of the members of the two groups appears to represent a paradox when it is compared with the reasons for retirement. sixty-two 
percent of the "job stress" group reported family incomes exceeding $\$ 40,000$ at the time of retirement, while only 50z of the "financially able" group reported that level of family income.

Two factors should be considered when examining this seemingly contradictory situation. First, the "financially able" group generally retired earlier than the "job stress" group, making the value of their income in "real" terms greater than a corresponding level in later years, owing to the inflationary affects of the economy since the 1960's. Second, the question addressed total family income, not total family worth, which might include real estate, and other investments.

Job stress appears to be more pronounced and lead to early retirement more frequently for the staff nurses (as opposed to the nurse managers). The staff nurses also had a lower level of formal nursing education.

Professional Perceptions and Early Retirement Fourteen of the closed-ended questions presented in the questionnaire addressed issues concerning the nursing profession and the work environment as perceived by the study sample. As with the demographic analysis, the sample was divided into those respondents 
who noted "job stress" as the primary reason for retiring early, and those who answered "financially able" as the primary reason for retirement. The data from these two groups were analyzed independently to determine and describe their general "professional perception" compositions.

The results of listing the number of respondents in each group who answered "yes" and "no" to the various questions related to professional perceptions are presented in Table 3. An interesting finding of this analysis is that 88 of the "job stress" group felt that "job stress increased with age" as compared to $67 \%$ of the "financially able" group; while only 50\% of the "job stress" group felt that "older nurses were discriminated against" as compared to $83 \%$ of the "financially able" group. From this finding it appears that job stress in older nurses may result from an inability to cope with age-related job factors such as loss of energy and poorer health rather than from age discrimination.

Both groups were unanimous in feeling that their efforts were appreciated by their patients; however, only $63 \%$ of the "job stress" group felt that such appreciation extended to their co-workers and peers. 
Table 3

Professional Perceptions of Subjects citing Job stress

Versus Financial Ability as the Primary Reason for

Retirement $(\mathrm{N}=14)$

Number of Responses

\begin{tabular}{lcc}
\hline & Job stress & Financial Ability \\
Response & Primary Reason & Primary Reason \\
\hline
\end{tabular}

Older nurses discriminated against?
a. Yes
4 (50\%)
$1(17 \%)$
b. No
$4(508)$
$5(83 \%)$

Job stress increases with age?
a. Yes
7 (88\%)
$4(67 \%)$
b. No
$1(13 \%)$
$2(33 \%)$

Effort appreciated by peers?
a. Yes
$5(63 \%)$
6 (100\%)
b. No
$3(388)$
0 (0z)

Note. Percentages are rounded to one-tenth percent. 
Table 3 (Continued - 2)

Professional Perceptions of Subjects Citing Job stress

Versus Financial Ability as the Primary Reason for

Retirement $(\mathrm{N}=14)$

Number of Responses

\begin{tabular}{lcc}
\hline & Job stress & Financial Ability \\
Response & Primary Reason & Primary Reason \\
\hline
\end{tabular}

Effort appreciated by patients?
a. Yes
8 (100\%)
$6(100 \%)$
b. No
0 (0₹)
0 (0z)

Job salary acceptable?
a. Yes
2 (258)
$2(338)$
b. No
$6(75 \%)$
4 (67\%)

Job reward systems appropriate?
a. Yes
1 (13\%)
1 (20\%)
b. No
7 (88\%)
$4(80 \%)$

Management aware of nursing problems?
a. Yes
0 (0z)
0 (0z)
b. No
8 (100\%)
$6(100 \%)$

Note. Percentages are rounded to one-tenth percent. 
Table 3 (Continued - 3)

Professional Perceptions of Subjects citing Job stress

Versus Financial Ability as the Primary Reason for

Retirement $(\mathrm{N}=18)$

Number of Responses

\begin{tabular}{lcc}
\hline & Job stress & Financial Ability \\
Response & Primary Reason & Primary Reason \\
\hline
\end{tabular}

skills adequate for job?
a. Yes
7 (88\%)
$6(100 \%)$
b. No
$1(13 \%)$
$0 \quad(08)$

Education adequate for job?
a. Yes
7 (88\%)
5 (83\%)
b. No
$1(138)$
$1(17 \%)$

Glad to be a nurse?
a. Yes
7 (88\%)
$6(100 \%)$
b. No
$1(13 \%)$
0 (08)

Advise young to become nurses?
a. Yes
5 (63\%)
$5(83 \%)$
b. No
3 (38t)
1 (17\%)

Note. Percentages are rounded to one-tenth percent. 
Both groups generally felt that their job skills and educational preparation were adequate for the work situation, and there was no discernable difference between the two groups in their perceptions of nursing salaries and reward systems. That is, both groups felt that the existing methods for recognizing professional worth were inadequate for the demands of the job. In addition, both groups were unanimous in their perception that management is unaware of the problems faced by nurses.

Finally, despite all of the reasons given for retiring early, 13 of the 14 questionnaire respondents, or $93 \%$ of the total sample, indicated that they were "happy to have been a nurse," and 10 of the 14 indicated that they would "advise a young person to enter the nursing profession." of those recommending nursing to the young, 63 of the "job stress" group so recommended, as compared to $83 \%$ of the financially able group.

\section{Content Analysis}

A content analysis was conducted to classify responses to the optional, unstructured, open-ended question that allowed respondents to write additional comments that they felt were appropriate to the subject 
matter." surprisingly, there was a large response to this option. The comments ranged from a short paragraph to three single spaced, type-written pages. Comments obtained through the open-ended question wfse analyzed and categorized into themes. The comments were helpful in qualifying many of the preset responses made in the closed-ended portion of the questionnaire.

The major themes identified through the open-ended questions can be stated as (a) poor retirement benefits for nurses, (b) weak nursing supervision, and (c) poor nursing "image." Three of the respondents elaborated at length upon the lack of sufficient retirement benefits provided to nurses. One respondent stated that after 20 years of full-time and part-time employment as a nurse, her total retirement benefit amounted to $\$ 6,000$. Another nurse said that she could not live on her retirement benefits and had to rely upon her investment income to survive. Financially able means different things to different people. Some of the respondents had investment income and spousal support to facilitate early retirement.

A more frequent theme mentioned in the open-ended section of the instrument was that of "weak nursing 
supervision." Four respondents, who had worked as staff nurses, mentioned the lack of support and supervision from supervisors as a factor leading to job stress, and two other nurses told of their frustrations in their role as supervisors. Weak supervision was expressed in many forms, ranging from a general lack of support for the staff nurse to "not disciplining younger nurses when they discuss private affairs in front of patients and other times when they lack 'professionalism'."

It is interesting to note that two of the nursing supervisors included in the study looked upon their years in a management role with more frustration than enthusiasm. One of the nursing supervisors said, "Work as a staff nurse was more rewarding than the last five years I worked as a supervisor. During those five years I felt that I was nothing but a 'paper pusher' and that I was attending a lot of very unproductive meetings."

The other supervisor stated, "I took a job in management because of the retirement benefits, but after years of working as a staff nurse the stress of being a supervisor was not worth it to me." From the comments of both staff nurses and nurse supervisors it 
would appear that support for either role from hospital administration is extremely important in alleviating job stress.

The poor "image" of the nursing profession, as reflected in a perceived lack of respect, and corresponding weak reward system were the most frequent issues discussed in the open-ended portion of the questionnaire. One staff nurse summarized the points raised by other nurses when she wrote:

I graduated [from nursing school] in 1948. Patients were treated by a paternal doctrine, nurses were never to question a physician, and approval was given to obedient, self sacrificing nurses. One soon learned to conceal intelligence and curiosity. Often you obtained order changes by manipulation. The system was rewarded by low pay and a great deal of anger from younger nurses. I attended my first national CNA (California Nurses Association) meeting in San Francisco and promptly joined a mass walk out over a salary issue. The subject had been raised and quickly squashed. The final CNA position was that, "Quibbling over salaries was beneath the dignity of a nurse." 
The reality of my first work place was disappointing. Nurses were their own worst enemy; accepting their inferior position on the health team, allowing themselves to be demeaned and used by their employers.

In summary, I've never regretted my nursing career. I'm proud to have been able to do "bedside nursing" and felt a lot of personal satisfaction in working with patients and co-workers. However, until the hospitals can begin to reward the nurses with better working conditions and wages they deserve for their expertise and responsibility, I would not advise anyone to enter the field. 


\section{Chapter 5 \\ CONCLUSIONS AND RECOMMENDATIONS}

Nurses are in short supply but in great demand in the $1980^{\prime} \mathrm{s}$. Taking an early retirement from nursing, prematurely ends a professional and demanding career, and takes from the health delivery system a scarce and valuable resource. Factors that influence seasoned professionals to end their careers early must be identified and understood by health care leaders so that appropriate action can be taken to preserve this valuable asset of the health care industry.

Little is known about why registered nurses retire early. Studies reported in the literature about workers in general suggest that being financially able, poor health, and poor working conditions lead to early retirement (Morse et al., 1883; Chan \& Fowles, 1980; Barfield \& Morgan, 1970). The lack of job satisfaction has been found to be associated with job turnover in nurses (Wolf, 1981). For the older nurses in this study the lack of job satisfaction may have lead to retirement rather than just changing jobs. other studies show that job satisfaction among registered nurses is influenced by supervisory assistance, task significance, task involvement, task autonomy, salary, 
and working conditions (Mottaz, 1988; Todd \& Wallace, 1987).

This study attempted to explore why registered nurses retired early. This chapter discusses the research results from the perspective of the conceptual framework.

Registered Nurses' Reasons for Early Retirement The results of this study indicate that registered nurses retire early from their profession for two primary reasons: (1) job stress, and (2) financial ability. Ninety-nine percent of the sample listed one or both of these factors as primary reasons for their retirement. Other factors that might influence the decision to retire early such as poor health, the need to care for a family member, or situations "external" to the health system environment, were infrequently mentioned by the sample.

Job stress was found to influence early retirement in a large portion of the sample. This was an influential factor among registered nurses who worked primarily in direct patient care (staff nurse) positions, who had less advanced formal education, and who felt increased job pressures placed upon them by hospital managers operating under the "Medicare DRG" 
and similar reimbursement systems. This finding is similar to that reported in the literature dealing with factors which decrease job satisfaction (Mottaz, 1988). The content analysis of responses solicited through an open-ended "comment" section of the research instrument revealed that many of the respondents felt strongly about a number of factors. They reported that their decisions to retire early were influenced by: (a) weak nursing supervision, (b) uninformed and unresponsive hospital management, (c) a lack of ability to influence decision making, and (d) a poor nursing "image" as reflected through insufficient compensation and reward systems.

The financial ability to retire early appears to be a "means to the end." Those nurses who noted "financial ability" as their primary reason for retiring also mentioned other reasons for retirement, both internal and external to the health care environment. These "secondary" reasons included, (a) job frustration, (b) "time to retire," (c) poor health, and (d) need to care for a family member. The financial ability to retire appears to be closely related to demographic characteristics of the study population. When demographic characteristics of 
the "financially able" group were compared to the entire sample, they generally: (a) had higher levels of formal education, (b) had worked as nurses more consistently and for longer periods of time, (c) had held higher positions of responsibility within the nursing profession when employed, and (d) had higher levels of "real" total family income at retirement. Interpretation of the Results From the Perspective of the Conceptual Framework King's conceptual framework presented in Figure 1 implies that the registered nurse's decision to retire prematurely from the nursing profession is the product of conflicting forces that play upon the individual's personal, interpersonal, and social systems. Also, these forces can emanate from sources both internal and external to the work environment. The conceptual model also suggests that the ultimate escape from these conflicting forces -- retirement from the profession --can be enhanced by an ability to maintain an acceptable lifestyle without the financial compensation earned as a registered nurse.

The results of the study appear to indicate that the current work environment of registered nurses in the hospital setting creates a situation that can lead 
to personal, interpersonal, and social system conflicts. These "conflict" situations can potentially affect nurses of all ages, however, older nurses seem less capable, or willing to deal with that conflict. Perhaps there are other reasons for these sources of conflict. These include: (a) the changes being imposed upon the health care industry by the government and other reimbursement agencies (interpersonal system), and (b) the lack of recognition by the health care system and by society in general of nurses as professionals (personal and social systems) despite efforts of nurses to promote that image. Conflict can accompany change in almost any level of human interaction if the change is not understood and handled properly. Recognizing the need for change, implementing and managing change are all difficult activities in any profession. The older registered nurse may be particularly vulnerable to frustration and stress brought about by change. These nurses were initially educated to follow ridged clinical protocols and be resistant to change.

This background may have proven to be a disservice to the older staff nurses as well as to nurse managers who are being asked to change and adapt to a new health 
care environment that stresses productivity through innovation and change. In such an environment, it is important to have support between and among staff nurses and their superiors as this is essential to the maintenance of equilibrium within the nurse interpersonal system. Support can be demonstrated by good communication, mutual goal setting, and recognition of achievements (King, 1981).

The results of the study indicate that nurses are not being supported in their job settings. one hundred percent of the study's sample population felt that hospital management was not aware of the problems faced by nurses.

\section{Recommendations}

owing to the small sample size and other limitations, findings of this study cannot be generalized to the larger population of nurses who retire prematurely. Nor is it likely that all the factors that influence nurses to retire early were uncovered. Since this issue has relative importance in developing strategies to keep older, experienced nurses in the profession, additional research in this area should be encouraged. It is recommended that a similar study be conducted on a much larger, more diverse 
sample. The sample should be selected randomly, be of sufficient size, and represent diverse geographical areas, so that it may be possible to uncover more variables affecting early retirement and to test relationships between variables using a statistical framework.

The results of this study, while descriptive in nature, provide insight into some of the major factors that influence nurses to retire early, and form the basis for a number of general recommendations. Early retirement for the older nurse is similar to job turnover in younger nurses. Both events can be influenced by job stress created by inadequate job satisfaction. The issue of job satisfaction among hospital nurses affects the entire nursing profession, and the profession, with support from the entire health care inaustry, neeàs to design anà implement stirategies to improve the working conditions of the hospital nurse.

One way to improve the working conditions of the hospital staff nurse is through programs designed to enhance nurse management skills. Such programs could be effective in educating new and existing nurse managers in the skills necessary to foster healthy 
relationships between the nurse managers and their staff so that staff feel more supported in their roles. Also, specific educational programs should be designed to develop skills for initiating, controlling and managing change within the nursing care system. These programs could be very usefil in reducing frustration and stress within and among nurses.

The search for recognition as professionals also appears to be a source of frustration among registered nurses (Mercer, 1987). The results of the study indicate a pervasive perception among retired nurses that the compensation and reward system was not commensurate with the level of education and responsibility required by the position. The issue of professionalism has become clouded with by other issues such as "comparable worth" and "sex discrimination" that make the nurses' search for proper recognition more complicated and frustrating. This study did not provide insight into the problem of how registered nurses can achieve professional recognition and commensurate compensation. It only suggests that this is needed to gain and maintain equilibrium within the nurses' personal and social systems as defined by the king model. 
Additional research must discover and test reward systems that not only reflect an appropriate level of professionalism, but that also are affordable in the eyes of society.

An interesting observation that can be drawn from the data and from the literature is that the health care industry provides relatively small retirement benefits to its employees (Chamber of Commerce of the United states, 1981). In so doing, the industry not only increases job frustration and stress by suggesting that the nursing profession occupies a relatively low level of social value, but also withnolas the financial leverage that would allow nurses to escape their frustrations and exercise early retirement.

More research is needed to answer the question: What is the relationship of more generous retirement benefits to age at the time of retirement for registered nurses? The literature indicates that women are more responsive than men to the incentives of increased wages and benefits (Rix \& Fisher, 1987); therefore, since registered nurses are predominantly women, an appropriate research hypothesis might be stated: If nurses were provided more generous retirement benefits, then more nurses would perceive a 
higher level of social worth and professionalism, thus remain in the profession longer.

The interpretations made from this descriptive study should be validated through more extensive research. If found to be statistically substantiated, the hypothesis presented here could form the basis of a program to reduce the exodus of registered nurses of all ages from the health care system and provide incentives to attract talented individuals into this important and demanding profession. 
REFERENCES 


\section{References}

Barfield, R. E., \& Morgan, J. N. (1970) . Early retirement: The decision and the experience and a second look. Ann Arbor, MI: University of Michigan Press.

Beutell, N. J., \& Brenner, O. C. (1987). Employee retirement decisions: Perceptions of American personnel administrators - a note. Personnel Review, 16, 31 .

Bower, F. L., \& Bevis, E. O. (1979). Fundamentals of nursing practice: Concepts, roles, and functions. st. Louis, MO: Mosby. Brooke, P. P., Russell, D. W., \& Price, J. L. (1988). Discriminate validation of measures of job satisfaction, job involvement, and organizational commitment. Journal of Applied Psychology, 7 ; 139. California Association of Hospitals and Health Systems. (1988). A report on the registered nurses shortage. sacramento, CA: CAHHS. Chamber of commerce of the United States. (1982). Employee benefits 1981. Washington, DC: Survey Research Center. Economic Policy Division. Report No. 11 . 
Chan, T., \& Fowles, D. G. (1980). The Older Worker: older Americans (NCA Report No. 6) - Washington, DC: United states Department of Health and Human Services. Office of Human Development Services Administration on Aging / National clearing House on Aging.

De Cotiis, T. A., \& Summers, T. P. (1987) . A path analysis of a model of the antecedents and consequences of organizational commitment. Human Relations, 26, 445 .

Dittmar, C. C. (1983). Retirement income issues for women and registered nurses. Kansas City, Mo: American Nurses' Association.

Hospitals not immune to high cost of stress. Hospitals, 62(19), 69.

Johnson, C. (Ed) . (1985). Facts about nursing. Kansas City, HO: American Nurses' Association. King, I. M. (1981). A theory for nursing. New York: John Wiley \& Sons.

Maddox, G. L. (Ed.) - (1987). The encyclopedia of aging. New York: Springer. Mckibbin, R. C. (1982). Nursing in the '80s: Key economic and employment issues. Kansas city, MO: American Nurses' Association. 
Mercer, R. G. (1987). Solution to nursing shortage involves a change in hospitals' view of nurses. Modern Healthcare, $17(25), 60$.

Morse, D. W., Dutka, A. B., \& Gray, S. H. (1983). Life after early retirement. Totowa, NJ: Rowman \& Allanheld.

Mottaz, C. J. (1988). Work satisfaction among hospital nurses. Hospital and Health Services Administration, $33(1)$, 57-74.

National Commission on Nursing. (1981). Initial report and preliminary recommendations. Chicago, IL: The Hospital Research and Educational Trust. (HRET Catalog No. 654100)

Parse, R. R. (1987). Nursing science, major paradigms, theories, and critiques. Philadelphia: พ.B. Saunders.

Polit, D. F., \& Hungler, B. P. (1987) - Nursing research, principles and methods ( 3 rd ed.). Philadelphia: Lippincott.

Rix, S. E., \& Fisher, P. (1982). Retirement-age policy: An international perspective. New York: Pergamon Press.

Sloan, F. A. (1975). The geographic distribution of nurses \& public policy. Bethesda, MD: U. S. 
Department of Health, Education, and Welfare. Streib, G. F., \& Schneider, C. J. (1971) . Retirement in American society: Impact and process. Ithaca, NY: Cornell University Press.

Todd, S. S., \& Wallace, L. F. (1987). Will inactive nurses help solve the nursing shortage? Nursing Management, 18(9), 101-107.

United states Public Law 97-248. Tax Equity and Fiscal Responsibility Act (TEFRA) of 1982. Washington, DC: U. S. Government Printing office, 1982. Wolf, G. A. (1981). Nursing Turnover: Some causes and solutions. Nursing Outlook, 29 233-236. 
APPENDIX A

Cover Letter 
(Date)

2355 San Miguel Drive

Walnut Creek, CA 94596

(Name)

(Address)

(Town, zip)

Dear (Name):

As I discussed with you over the phone recently, I am conducting a research project to identify the factors that influence registered nurses to retire before the traditional retirement age. This research is being conducted as a thesis project for a Masters of science in Nursing degree at San Jose state University. Please complete the enclosed Consent Form and Questionnaire and return them to me as soon as possible so that your responses can be included in the study. As I mentioned, your identity will remain confidential, but the data will be used for statistical computations. Thank you for your help. This information could be invaluable to future generations of nurses.

sincerely,

Phyllis Alexander BS, RN

Enclosures 
APPENDIX B

Consent Form

71 
Consent Form

You are invited to participate in a study of retired nurses. We hope to learn what factors influence nurses in choosing early retirement. You were selected as a possible participant in the study because you worked over ten consecutive years in the nursing profession and you retired before age 62 .

If you decide to participate in the study you will be given a four page questionnaire to fill out. It is a simple questionnaire and should not take over thirty minutes.

Any information that is obtained in connection with this study and that can be identified with you will remain confidential and will be disclosed only with your permission or as required by law. If you give us your permission by signing this document, this information will be compiled for a research project, for a masters degree in nursing, at san Jose state University.

If you decide to participate, you are free to withdraw your consent and to discontinue participation at any time without prejuaice. If you have any questions please call me, Phyllis Alexander, BS, RN, 415-930-0783, or my advisor, Julie corbin, DN SC., RN at $408-277-2694$.

You are making a decision whether or not to participate. Your signature indicates that you have decided to participate having read the information provided above. 
APPENDIX C

Questionnaire

73 
1. Current Age:

3. Gender:

Male []

5. Education:

Diploma

AA

BSN

Masters

Other degree

$\begin{array}{ll}{[} & ] \\ {[} & ] \\ {[} & ] \\ {[} & ] \\ {[} & ]\end{array}$

7. RN Position status

at retirement:

Staff Nurse

Head Nurse

Supervisor

other

$\left.\begin{array}{ll}{[} & ] \\ {[}\end{array}\right]$

9. At retirement what was your clinical area?

Medical/Surgical [ ]

Maternal/Child

Critical care

operating Rm/PAR

Emergency Room

Management

$\begin{array}{ll}{[} & ] \\ {[} & ] \\ {[} & ] \\ {[} & ] \\ {[} & ]\end{array}$

11. During your last year employed as an RN

your annual salary was:

Less than $\$ 15,000$ [ ]

$\$ 15,000-20,000$

$\$ 20,000-30,000$

$\$ 30,000-40,000$

Over $\$ 40,000$

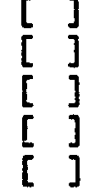

13. Your Marital Status at retirement was:

Married

single
2. Age at Retirement:

4. Race:

White

Black

Hispanic

Asian

American Indian

Other

$\begin{array}{ll}{[} & ] \\ {[} & ] \\ {[} & ] \\ {[} & ] \\ {[} & ]\end{array}$

6. How long did you work as an RN.?

10-15 years

16-20 years

21-25 years

over 25 years

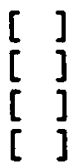

8. At retirement did you work full time?

Yes

No

If No, did you work

$>20$ hours/week [ ]

$\leq 20$ hours/week [ ]

10. How long did you work in your last position?

Less than 5 years [ ]

5-10 years

$10-15$ years

15-20 years

Over 20 years

$\begin{array}{ll}{[} & ] \\ {[} & ] \\ {[} & ] \\ {[} & ]\end{array}$

12. During your last year employed as an RN your total family income was:

Less than $\$ 15,000$

$\$ 15,000-20,000$

$\$ 20,000-30,000$

$\$ 30,000-40,000$

Over $\$ 40,000$ 
14. If currently married

is your spouse retired? Yes

No

Not Applicable

$\left[\begin{array}{l}{[} \\ {[}\end{array}\right]$

16. Were you in good health

at your retirement?

Yes

No

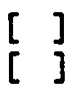

15. Was your spouse in good health at time of your retirement? Yes

No

Not Applicable

17. Currently your total family income is: Less than $\$ 15,000$ $\$ 15,000-20,000$

18. Currently your retirement income is:

Less than $\$ 15,000$ $\$ 15,000-20,000$ $\$ 20,000-30,000$ $\$ 30,000-40,000$ Over $\$ 40,000$

$\$ 20,000-30,000$

$\$ 30,000-40,000$ Over $\$ 40,000$

19. At retirement did you belong to a labor union? Yes

No

[]

20. What is the main reason you retired?

Health

Financially able to

Job Stress

Encouraged by management other

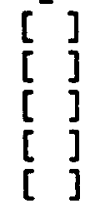

21. Did you have retirement benefits other than social security at retirement?

Yes No

22. Do you own your own home?

[ ] [ ]

23. Did you pre-plan your retirement?

[ ] [ ]

23. Were you asked to retire by a supervisor? [ ] [ ]

24. Would you have changed jobs within the facilicy you were working in at the time of retirement if asked to?

25. Do you have friends or relatives who retired early? 
Q U E S T I O N N A I R E

Yes No

26. Is your retirement income adequate to live on?

27. Did you feel job stress had increased as you grew older?

28. Did you feel that older nurses were discriminated against?

29. Are you happy that you chose to be a nurse?

[ ] [ ]

[ ] [ ]

30. Would you advise a young person to enter nursing?

31. Did you feel your years of experience were appreciated by co-workers?

[ ] [ ]

[ $\left.\begin{array}{lll}] & {[}\end{array}\right]$

[ ] [ ]

32. Did you feel your years of experience were appreciated by patients?

33. Did you feel your nursing salary was adequate for the work you were doing?

34. Do you feel that your retirement income is adequate to live on?

35. Did you feel that management was aware of problems faced by nurses?

[ ] [ ]

[ ] [ ]

[ ] [ ]

[ ] [ ]

[ ] [ ]

36. Do you feel that young nurses have realistic expectations of nursing as a career?

37. Do you feel that the reward system for nurses is appropriate?

38. Do you feel your nursing skills were adequate for your job?

39. Do you feel your education was adequate for your job? 
Q U E S T I O N N A I R E

40. Please use the space below for additional comments you feel are appropriate to the subject matter.

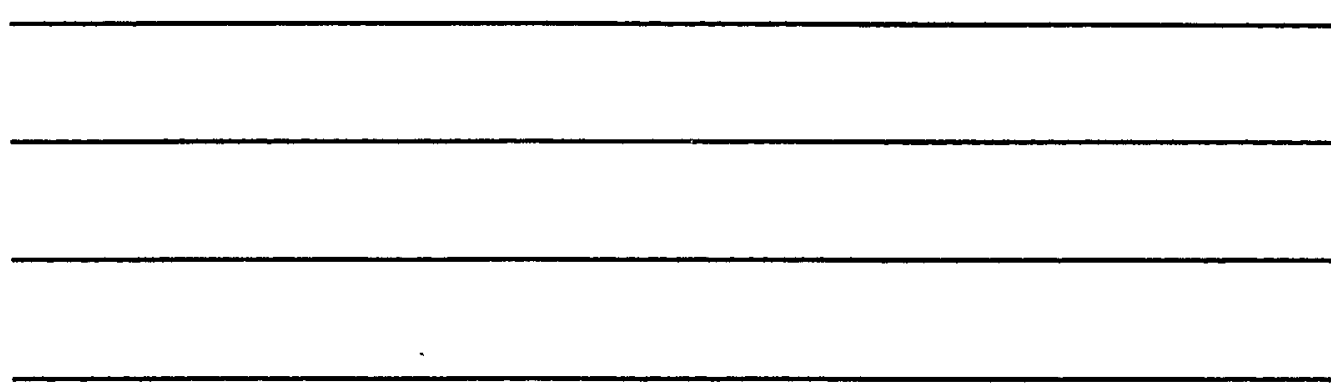

page 4 